\title{
Vorticity Equation of Transient Ultra-Long Waves in Middle Latitudes in Winter Regarded as Langevin's Equation in Brownian Motion
}

\author{
By K. Gambo \\ Geophysical Institute, Tokyo University, Tokyo 103 \\ (Manuscript received 31 July 1981)
}

\begin{abstract}
It is shown that the spectral density of vorticity of transient ultra-long waves in the frequency domain is proportional to the minus second power of the frequency in middle latitudes in winter season. In order to explain the physical background of the above result, the vorticity equation of transient ultra-long waves is examined if there is the possibility to rewrite in the same form with Langevin's equation in Brownian motion. By making use of data in two winter seasons of 1971-1972 and 1975-1976, it is shown that the vorticity equation of ultra-long waves in middle latitudes in winter may be treated in the same way with Langevin's equation in Brownian motion.
\end{abstract}

\section{Introduction}

In the previous papers (Gambo, 1979), we proposed that the spectral density of vorticity of transient ultra-long waves in the frequency domain is approximately proportional to the minus second power of the frequency in middle latitudes in winter season. In order to explain the physical background of the result mentioned above, the vorticity equation of transient ultralong waves at $500 \mathrm{mb}$ level was discussed from the standpoint of Langevin's equation in Brownian motion (Yaglom, 1962). That is, the vorticity equation of transient ultra-long waves is approximately expressed in terms of such as the rate of change of vorticity, $\partial \zeta / \partial t$ ( $t$ : time), the horizontal advection term of absolute vorticity, $V_{g} \cdot \nabla(\zeta+f) \quad\left(V_{g}:\right.$ horizontal geostrophic wind vector, $f$ : Coriolis parameter), the divergence term, $f \operatorname{div} V(V:$ horizontal wind vector) and the frictional term, $a \zeta$ ( $a$ : constant). In this expression, we assume that the vorticity $\zeta$ is regarded as the velocity of a particle immersed in a fluid, and the frictional term is considered as the friction force acting on the particle. Further we assume that the horizontal advection term of absolute vorticity and the divergence term are regarded as an additional "purely random" force due to the collision of molecules of the fluid with a particle.

However, the data of height which we used in the previous paper were limited to those at $500 \mathrm{mb}$ level. Therefore only the time-series of horizontal advection term of vorticity and socalled $\beta$-term in the vorticity equation was examined whether the time series of these terms was a stationary random process with a white noise time series or not. The time series of divergence term in the vorticity equation was not able to discuss due to the lack of threedimensional data of height. In this sense the discussion in the previous paper was not complete. In this paper we re-examine the timeseries of horizontal advection term of vorticity, $\beta$-term and divergence term in the vorticity equation by making use of three-dimensional data of height whether the assumption of stationary random process with a white noise time-series for each terms in the vorticity equation is reasonable or not.

\section{Analysis and data}

The basic data used in the analyses are height $z$ and temperature $T$ at $850 \mathrm{mb}, 700 \mathrm{mb}, 500 \mathrm{mb}$ and $300 \mathrm{mb}$ levels over a period of 91 days for two winter seasons of 1 December 1971 to 29 February 1972 and 1 December 1975 to 29 February 1976. The daily data during these 
periods were obtained from the NMC Washington analyses.

The reason why we select two winter seasons of 1971-1972 and 1975-1976 is that seasonal means of atmospheric flows in winter seasons of 1971-1972 and 1975-1976 are quite different. That is, the zonal wave number $k=2$ predominates in the winter of 1971-1972, while we observe the predominant zonal wave number $k=3$ in the winter of $1975-1976$ such as shown in Figs. 1 and 2. The contour in Figs. 1 and 2 shows the monthly mean height $z^{*}(\varphi)$ of January at $500 \mathrm{mb}$ level. Here $z^{*}(\varphi)$ is defined as the height, including only three zonal wave components, i.e., $z^{*}(\varphi)=\sum_{k=1}^{3} z_{k}(\varphi) \cos k\left(\lambda-\alpha_{k}(\varphi)\right)$ where $\lambda$ and $\varphi$ are longitude and latitude respectively and $z_{k}(\varphi)$ and $\alpha_{k}(\varphi)$ are amplitude and phase of height $z$ for zonal wave number $k$ respectively. Since we are concerned with the daily fluctuation of vorticity deviation from the seasonal mean, the selection of two winter seasons mentioned above may be interesting ones in a sense that the basic mean states in winter seasons of 19711972 and 1975-1976 are different each other.

\section{Vorticity equation and vertical p-velocity}

The vorticity equation in the $(x, y, p)$ coordinates for ultra-long waves may be written under the assumption of geostrophic approximation as follows:

$$
\frac{\partial \zeta}{\partial t}+V_{g} \nabla \zeta+\beta v=f \frac{\partial \omega}{\partial p}
$$

where $\zeta$ is the vorticity, $V_{\mathrm{g}}$ is the horizontal vector of geostrophic wind, $f$ is the Coriolis parameter, $\beta=\partial f / \partial y$ and $\omega$ is the vertical $p$ -

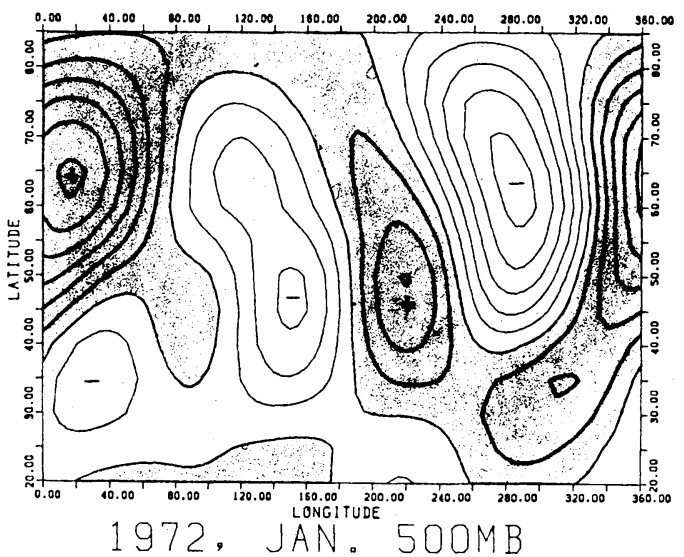

Fig. 1 Mean $500 \mathrm{mb}$ height for January 1972, including only zonal harmonics 1 to 3 . Contour interval is $50 \mathrm{~m}$.

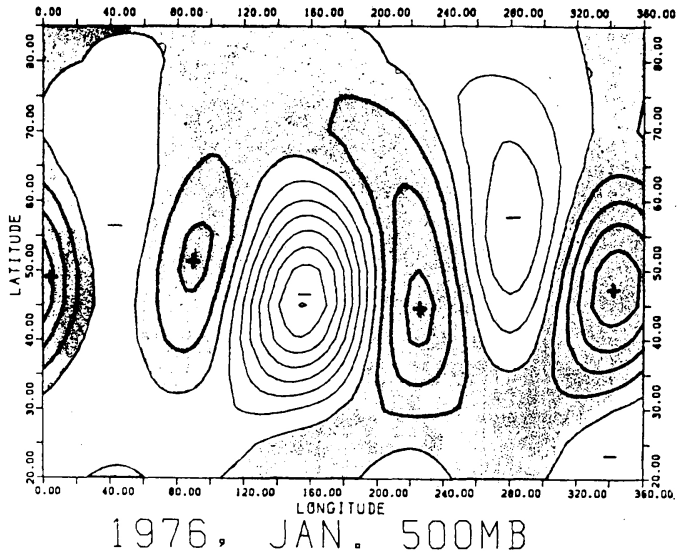

Fig. 2 As in Fig. 1 except mean $500 \mathrm{mb}$ height for January 1976.

velocity.

Since the data of height are given at gridpoint in the $(\lambda, \varphi)$ coordinates $(\lambda$ : longitude, $\varphi$ : latitude) and we are concerned with the vorticity equation only in middle latitudes, we assume that the vorticity equation (3.1) is approximately expressed as follows:

$$
\frac{\partial \zeta}{\partial t}+u_{g} \frac{1}{r \cos \varphi} \frac{\partial \zeta}{\partial \lambda}+v_{g} \frac{\partial \zeta}{r \partial \varphi}+\beta v_{g}=f_{0} \frac{\partial \omega}{\partial p}
$$

where $u_{g}$ and $v_{g}$ denote horizontal geostrophic winds in $\lambda$ (eastward) and $\varphi$ (northward) directions respectively, $f_{0}=f$ at $\varphi=\varphi$, and $\beta=2 \Omega / r$ $\cos \varphi$ ( $\Omega$ : earth's angular velocity of rotation, $r$ : radius of earth). In the numerical computation of the $k$-component of vorticity, $\zeta_{k}$ ( $k$ : zonal wave number) at latitude $\varphi$, we assume that

$$
\begin{aligned}
& \zeta_{k}=\left(g / f_{0}\right) \nabla^{2} z_{k} \\
& =\frac{g}{f_{0} r^{2} \cos \varphi}\left\{\frac{\partial}{\partial \varphi}\left(\cos \varphi \frac{\partial z_{k}}{\partial \varphi}\right)-\frac{1}{\cos \varphi} \cdot \frac{\partial^{2} z_{k}}{\partial \lambda^{2}}\right\} \\
& \frac{\partial^{2} z_{k}}{\partial \lambda^{2}}=-k^{2} z_{k} \\
& \frac{\partial z_{k}}{r \partial \varphi} \fallingdotseq \frac{1}{2 r \Delta \varphi}\left[\left(z_{k}\right)_{\varphi+\Delta \varphi}-\left(z_{k}\right)_{\varphi-\Delta \varphi}\right] \\
& \frac{\partial^{2} z_{k}}{\partial \varphi^{2}}=\frac{1}{\Delta \varphi^{2}}\left[\left(z_{k}\right)_{\varphi+\Delta \varphi}+\left(z_{k}\right)_{\varphi-\Delta \varphi}-2\left(z_{k}\right)_{\varphi}\right]
\end{aligned}
$$

where $z_{k}$ is the $k$-component of height, $g$ is the acceleration of gravity, $\Delta \varphi=5^{\circ}$ latitude and $f_{0}$ is constant value of $f$ at $\varphi=45^{\circ}$. Concerning the geostrophic winds of $u_{g}$ and $v_{g}$, we assume that. 


$$
\begin{aligned}
& u_{g}=-\frac{g}{f_{0}} \frac{1}{r \cos \varphi} \frac{\partial z}{\partial \lambda} \\
& v_{g}=\frac{g}{f_{0}} \frac{\partial z}{r \partial \varphi}
\end{aligned}
$$

Thus, the advection term and $\beta$-term in (3.2) are computed from the height $z$ by the finitedifference formula with grid-lengths of $\Delta \lambda=5^{\circ}$ longitude and $\Delta \varphi=5^{\circ}$ latitude respectively. The term of $\partial \zeta / \partial t$ in (3.2) at time $t$ is estimated approximately as follows*:

$$
\frac{\partial \zeta}{\partial t}=\frac{1}{2 \text { days }}[\zeta(t+1 \text { day })-\zeta(t-1 \text { day })]
$$

In this way the daily values of the left-hand side of (3.2) are computed from those of height $z$.

The value of $\omega$ is obtained by integrating the vorticity equation (3.2) with respect to $p$. Since we use the data of height at $850 \mathrm{mb}, 700 \mathrm{mb}$, $500 \mathrm{mb}$ and $300 \mathrm{mb}$, the following approximations for obtaining the values of $\omega$ at $850 \mathrm{mb}$, $700 \mathrm{mb}, 500 \mathrm{mb}$ and $300 \mathrm{mb}$ are used.

$$
\begin{aligned}
\omega_{850} & =\omega_{s}-\frac{1}{f_{0}}\left(\frac{\partial \zeta}{\partial t}+\boldsymbol{V} \cdot \nabla \zeta+\beta v\right)_{850} \\
\quad & \left(p_{s}-850 \mathrm{mb}\right) \\
\omega_{700} & =\omega_{850}-\frac{1}{2 f_{0}}\left[\left(\frac{\partial \zeta}{\partial t}+V \cdot \nabla \zeta+\beta v\right)_{850}\right. \\
& \left.+\left(\frac{\partial \zeta}{\partial t}+V \cdot \nabla \zeta+\beta v\right)_{700}\right] \cdot(150 \mathrm{mb})(3.11) \\
\omega_{500} & =\omega_{700}-\frac{1}{2 f_{0}}\left[\left(\frac{\partial \zeta}{\partial t}+V \cdot \nabla \zeta+\beta v\right)_{700}\right. \\
& \left.+\left(\frac{\partial \zeta}{\partial t}+V \cdot \nabla \zeta+\beta v\right)_{500}\right] \cdot(200 \mathrm{mb})(3.12) \\
\omega_{300} & =\omega_{500}-\frac{1}{2 f_{0}}\left[\left(\frac{\partial \zeta}{\partial t}+V \cdot \nabla \zeta+\beta v\right)_{500}\right. \\
& \left.+\left(\frac{\partial \zeta}{\partial t}+\boldsymbol{V} \cdot \nabla \zeta+\beta v\right)_{300}\right] \cdot(200 \mathrm{mb})(3.13)
\end{aligned}
$$

Here $p_{s}$ is the surface pressure expressed in unit of $\mathrm{mb}, \omega_{s}=(\omega)_{p_{n} p_{s}}$ and the suffix $i$ denotes the value at the level of $i$-mb. For the value of $\omega_{s}$ we assume that the surface vertical $p$-velocity is caused by surface orography where the standard pressure is $p_{g}$, and also by Ekman pumping resulting from the viscosity in the Ekman layer. Thus, the vertical $p$-velocity at $p=p_{s}$ is given as (see Derome and Wiin-Nielsen, 1971),

* Since the unit of $\Delta t$ is 1 day, the accuracy of approximation of (3.9) will not expected to be reasonable for waves with relatively short life time.

$$
\omega_{s}=V_{850} \cdot \nabla p_{g}-\frac{p_{s} E}{f_{0}} \zeta_{850}
$$

In (3.14) the horizontal velocity vector and the vorticity are approximated by those at $850 \mathrm{mb}$ level. $E$ is the friction coefficient and will be treated as a constant $\left(2 \times 10^{-6} \mathrm{~s}^{-1}\right)$. The value of $p_{g}$ is computed from the height data of surface orography arranged by Berkofsky and Bertoni (1955). However, we assume that $p_{g}=700 \mathrm{mb}$ when $p_{g} \leqq 700 \mathrm{mb}$. The rough accuracy of $\omega$ obtained by (3.10)-(3.13) will be checked in section 6 from the stand-point of estimation of geographical distribution of heat source/sink in the atmosphere. Generally speaking, the accuracy of computed $\omega$ seems to decrease with height in a sense that $\omega(p)$ does not converge to zero with the decrease of $p$.

\section{Vorticity equation of transient ultra-long waves at $750 \mathrm{mb}$ level}

Since we can obtain the value of $\omega(p)$ at $p=$ $1,000 \mathrm{mb}$ and $p=500 \mathrm{mb}$ from the height data as mentioned in section 3 , the vorticity equation of transient ultra-long waves at $750 \mathrm{mb}$ level may be written approximately as follows:

$$
\frac{\partial \zeta_{750}}{\partial t}+(V \cdot \nabla \zeta)_{750}+\beta v_{750}=\frac{f_{0}}{\Delta p}\left(\omega_{1000}-\omega_{500}\right)
$$

where $\Delta p=500 \mathrm{mb}$ and suffix $i$ denotes the value at the level of $i$-mb as mentioned before.

Rearrangement of (4.1) gives the following equation as

$$
\begin{aligned}
& \frac{\partial \zeta_{750}}{\partial t}-\frac{f_{0}}{\Delta p} \omega_{1000} \\
& \quad=-\left[(V \cdot \nabla \zeta)_{750}+\beta v_{750}+\frac{f_{0}}{\Delta p} \omega_{500}\right] \\
& \quad \equiv F\left(\zeta_{750}, u_{750}, v_{750}, \omega_{500}\right)
\end{aligned}
$$

In the following discussion, we assume that $\omega_{1000}=\omega_{s}$.

Now we consider the time series of right-hand side in (4.2) or (4.3) in two winter seasons of 1971-1972 and 1975-1976. The vorticity $\zeta_{750}$ and horizontal wind velocities $\left(u_{750}, v_{750}\right)$ at 750 $\mathrm{mb}$ level are computed from the height $z_{750}$ which is estimated by the hydrostatic relation from the height $z_{700}$ and the temperature $T_{700}$ at $700 \mathrm{mb}$ level. Thus, the value of $F$ in (4.3) is easily estimated by the finite-difference formula with grid-length of $\Delta \lambda=5^{\circ}$ longitude and $\Delta \varphi=5^{\circ}$ latitude respectively.

If we expand (4.3) into the Fourier series in the longitudinal direction, we have 


$$
\frac{\partial \zeta^{k_{750}}}{\partial t}-\frac{f_{0}}{\Delta p} \omega^{k_{1000}}=F^{k}(\varphi, t)
$$

where the superscript $k$ denotes the amplitude of $k$-component of the Fourier series, i.e.,

$$
F=R_{e}\left(\sum_{k} \zeta_{750} e^{i k \lambda}\right), \quad \omega_{1000}=R_{e}\left(\sum_{k} \omega^{k}{ }_{1000} e^{i k \lambda}\right)
$$

and

$$
F=R_{e}\left(\sum_{k} F^{k} e^{i k \lambda}\right)
$$

In order to check the characteristic feature of time series of $F^{k}(\varphi, t)$ for ultra-long waves in (4.4), we compute the spectral density of $F^{k}$ $(\varphi, t)$ in the frequency domain $\nu . *$ As the typical example of ultra-long waves, the results for $k=2$ in two winter seasons of 1971-1972 and 19751976 are shown in Figs. 3 and 4 with black dots. The spectral densities are computed at $\varphi=45^{\circ}, 50^{\circ}$ and $55^{\circ} \mathrm{N}$ respectively and the mean value of spectral densities thus obtained is finally shown in the figure. White circles in the figure

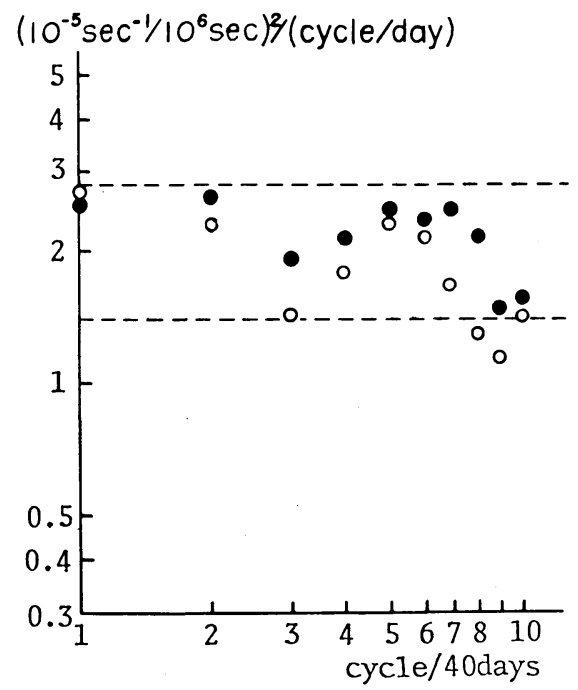

Fig. 3 Mean spectral densities of $F^{k}(\varphi, t)$ and $\left(\frac{\partial \zeta^{k}{ }_{750}}{\partial t}-\frac{f_{0}}{\Delta p} \omega^{k}{ }_{1000}\right)$ for $k=2$ in the frequency

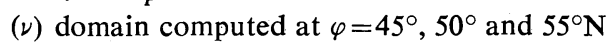
in the winter season of 1971-1972. Black dot and white circle correspond to the spectral densities of $F^{k}(\varphi, t)$ and $\left(\frac{\partial \zeta^{k}{ }_{750}}{\partial t}-\frac{f_{0}}{\Delta p} \omega^{k}{ }_{1000}\right)$ respectively. Units of spectral density and $\nu$ are $\left(10^{-5} \mathrm{~s}^{-1} / 10^{6} \mathrm{~s}\right)^{2} /($ cycle/day) and cycle $/ 40$ days respectively. Straight dotted lines correspond to lines of spectral density $=$ const.

* Details of spectral analysis which we use are explained in the previous paper (Gambo, 1979).

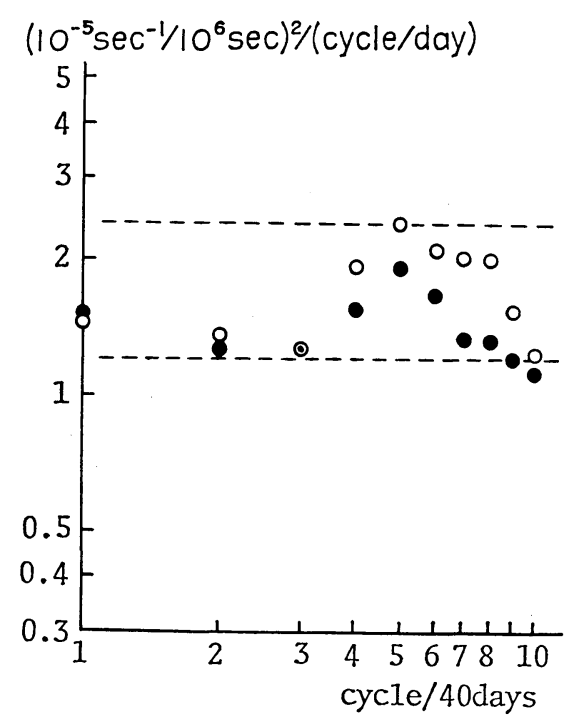

Fig. 4 As in Fig. 3 except in the winter season of 1975-1976.

denote the spectral densities of the left-hand side in (4.4), i.e., $\left.\left\{\left(\partial \zeta^{k} 750 / \partial t\right)-\left(f_{0} / \Delta p\right) \omega^{k}{ }_{1000}\right)\right\}$. As mentioned before we assume that $\omega_{1000}=\omega_{s}$. Therefore the spectral density of $\omega^{k}{ }_{1000}$ is obtained from that of $\omega_{s}{ }^{k}$. The small difference between black dot and white circle may come from the approximate estimation of $\omega_{500}$ such as mentioned in (3.10)-(3.13). As may be seen in Figs. 3 and 4 , the magnitude of spectral density of $F^{k}$ for $k=2$ is regarded as constant with respect to the frequency $\nu$ in a sense of first approximation. Therefore we may be able to assume that $F^{k}$ for $k=2$ is a stationary random process with a white-noise time-series. Similar results with Figs. 3 and 4 are also obtained in cases of $k=1$ and 3. Concerning the result that the value of $F^{k}$ is regard as constant with respect to the frequency $\nu$, it will be mentioned that the nonlinear interaction of baroclinic waves and ultra-long waves plays an important role in estimating $(V \cdot \nabla \zeta)^{k}$ in (4.3) (Gambo, 1979).

Since $\omega_{1000}$ is given by (3.14), we may rewrite the equation (4.4) as follows

$$
\frac{\partial \zeta^{k_{750}}}{\partial t}+a \zeta_{850}^{k_{80}}-\frac{f_{0}}{\Delta p}\left(V_{850} \cdot \nabla p_{g}\right)^{k}=F^{k}(\varphi, t)
$$

where $a=\left(p_{s} / \Delta p\right) E \doteqdot 2 E$ *and $\left(V_{850} \cdot \nabla p_{g}\right)^{k}$ denotes the $k$-component of $\left(V_{850} \cdot V p_{g}\right)$.

From the standpoint of spectral density in the

* If we use the value of $E=2 \times 10^{-6} \mathrm{~s}^{-1}, \mathrm{a} \fallingdotseq 1 / 2.9$ day. 
frequency domain, we may expect that the third term of the left-hand side in (4.5), $-f_{0} / \Delta p$ $\left(V_{850} \cdot \nabla p_{g}\right)^{k}$ plays an minor contribution to the estimation of spectral density in (4.5) in case of relatively high frequency domain, because $p_{g}$ is constant with time and $V_{850} \cdot \nabla p_{g} \approx U_{850}\left(\partial p_{g} /\right.$ $\partial x)$ ( $U$ : zonal mean wind). In order to support the discussion mentioned above, the spectral densities of $\omega^{k} 1000$ and $\zeta_{850}$ for $k=2$ in the winter of 1971-1972 are shown in Figs. 5 and 6 respectively. The values in Figs. 5 and 6 are mean values computed at $\varphi=45^{\circ}, 50^{\circ}$ and $55^{\circ} \mathrm{N}$. The straight line in Figs. 5 and 6 denotes that the spectral density is proportional to the minus second power of the frequency and it is written for the sake of reference. Considering that spectral densities of $\omega_{1000}$ and $\zeta_{850}$ in Figs. 5 and 6 are shown in units of $(\mathrm{mb} / \mathrm{hr})^{2}$ and $\left(10^{-5} \mathrm{~s}^{-1}\right)^{2}$ respectively and $\left(p_{s} / f_{0}\right) E \zeta_{850} \fallingdotseq 0.72 \zeta_{850}(\mathrm{mb} / \mathrm{hr})$ $\left(1 / 10^{-5} \mathrm{~s}^{-1}\right)$ at $\varphi=45^{\circ}$, we may be able to assume in the frequency ( $\nu$ ) domain such as $\nu>2$ cycles/ 40 days that spectral density of $\omega^{k}{ }_{1000} \approx$ spectral density of $\left(p_{s} / f\right) E \zeta_{850}$.

Assuming further that $\zeta_{850}^{k} \approx \zeta_{7500}^{k}$, the equa-

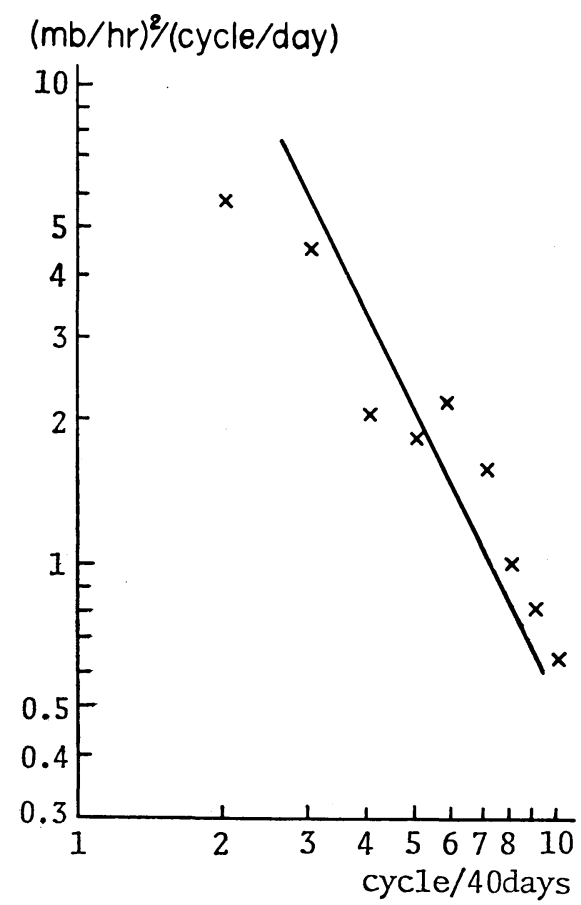

Fig. 5 Mean spectral density of $\omega^{k}{ }_{1000}$ for $k=2$ in the frequency $(\nu)$ domain computed at $\varphi=45^{\circ}$, $50^{\circ}$ and $55^{\circ} \mathrm{N}$ in the winter season of 1971 1972. Units of spectral density and $\nu$ are $(\mathrm{mb} /$ $\mathrm{hr})^{2 /(c y c l e / d a y)}$ and (cycle/40 days) respectively.

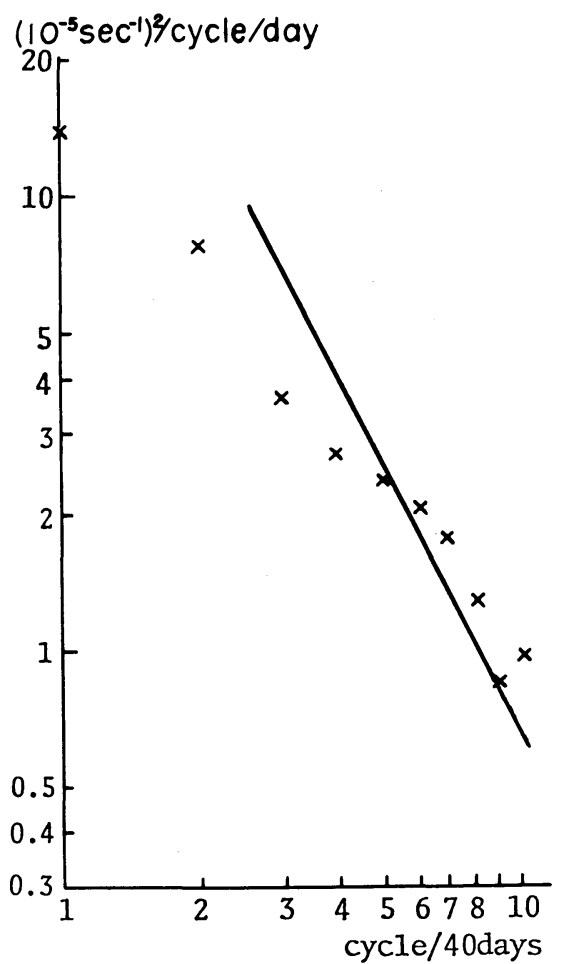

Fig. 6 Mean spectral density of $\zeta^{k}{ }_{550}$ for $k=2$ in the frequency $(\nu)$ domain computed at $\varphi=45^{\circ}$, $50^{\circ}$ and $55^{\circ} \mathrm{N}$ in the winter season of 1971-1972. Units of spectral density and $\nu$ are $\left(10^{-5} \mathrm{~s}^{-1}\right)^{2} /$ (cycle/day) and (cycle/40 days) respectively.

tion (4.5) may be approximated when we consider to estimate the spectral density in the frequency

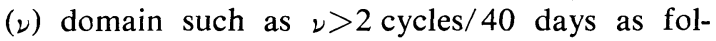
lows:

$$
\frac{\partial \zeta^{k} 750}{\partial t}+a^{\prime} \zeta_{750}{ }^{k}=F^{k}
$$

where $a^{\prime}=a \cdot \zeta^{k} 850 / \zeta^{k} 750$.

If $F^{k}$ and $a^{\prime}$ are regarded as the "purely random". force and the damping coefficient respectively, the equation (4.6) will be considered as Langevan's equation in Brownian motion as mentioned in the introduction of this paper (Yaglom, 1962).

\section{Spectral density of vorticity for transient ultra-long waves}

In the foregoing section it is mentioned that the spectral density of $\zeta_{750}$ is approximately obtained from (4.6). On the other hand, in the case of ultra-long waves $F^{k}$ in (4.6) is regarded as a stationary random process with a whitenoise time series as mentioned in section 4 . Thus, the spectral density of $\zeta_{750}$ in the frequency ( $\nu$ ) 
domain is given as follows (Yaglom (1962), Lumley and Panofsky (1964)):

$$
\text { spectral density of } \zeta^{k_{750}}=\frac{A^{k}}{a^{\prime 2}+\nu^{2}}
$$

where $A^{k}$ is the spectral density of $F^{k}$.

Since $a^{\prime} \approx a \approx 1 / 2.9$ day and $A^{k} \approx$ const., we have

$$
\text { spectral density of } \zeta_{750^{k}}=\frac{A_{k}}{\nu^{2}}
$$

in the frequency domain where $a^{\prime} \ll \nu$. The computed spectral densities of $\zeta^{k}{ }_{750}$ for $k=2$ in two winter seasons of 1971-1972 and 1975-1976 are shown in Figs. 7 and 8 respectively. The results in Figs. 7 and 8 are mean values of spectral densities of $\zeta^{k}{ }_{750}$ computed at $\varphi=45^{\circ}, 50^{\circ}$ and $55^{\circ} \mathrm{N}$. The straight line in Figs. 7 and 8 denotes the value of $A^{k / \nu^{2}}$ where we assume as

$$
A^{k}=3.8 \text { in unit of (cycle/day)/10 } 12 \mathrm{~s}^{2} \text {. }
$$

This straight line is written for the sake of convenience refering the value of $A^{k}$ in Fig. 3. From the results of Figs. 7 and 8 we may be

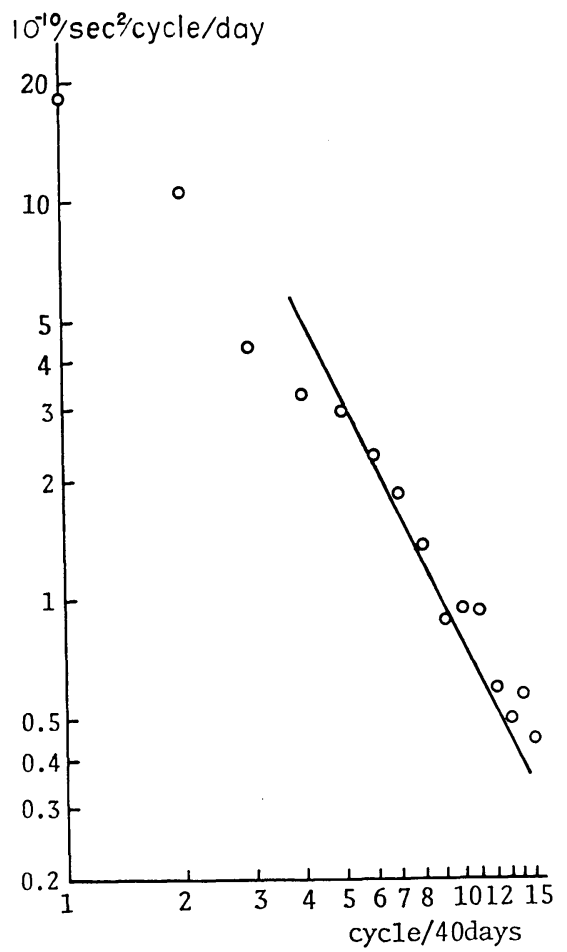

Fig. 7 Mean spectral density of $\zeta^{k} 750$ for $k=2$ in the frequency $(\nu)$ domain computed at $\varphi=45^{\circ}$, $50^{\circ}$ and $55^{\circ} \mathrm{N}$ in the winter season of 1971 1972. Units of spectral density and $\nu$ are $\left(10^{-5}\right.$ $\left.\mathrm{s}^{-1}\right)^{2} /($ cycle/day) and (cycle/40 days) respectively. Straight line denotes that $A^{k / \nu^{2}}=$ const.

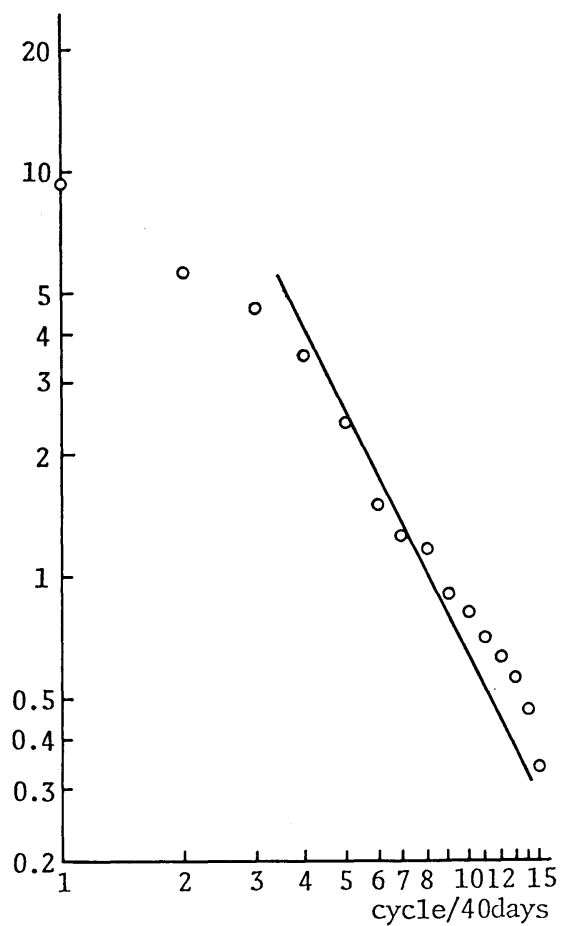

Fig. 8 As in Fig. 7 except in the winter season of 1975-1976.

able to regard that the time series of vorticity for ultra-long waves in middle latitudes in winter is regarded as a stochastic process and the spectral density of vorticity for ultra-long waves is proportional to the minus second power of the frequency.

Similar discussion will be done in the case of spectral density of $\zeta^{\mathrm{k}}{ }_{500}$. In this case we assume that $(\omega)_{p=0}=0$ and the vorticity equation at $500 \mathrm{mb}$ level may be written as follows:

$$
\frac{\partial \zeta_{500^{k}}}{\partial t}+(\boldsymbol{V} \cdot \nabla \zeta)^{k_{500}}+\beta v^{k_{500}}=\frac{f_{0}}{\Delta p^{\prime}} \omega^{k_{1000}}
$$

where $\Delta p^{\prime}=1,000 \mathrm{mb}$.

If the spectral density of $(V \cdot \nabla \zeta+\beta v)^{k}{ }_{500}$ in the frequency domain for ultra-long waves is regarded as constant with respect to the frequency 2 in a sense of a first approximation, ${ }^{*}$ the spectral density of $\zeta^{k}{ }_{500}$ may be expressed in the similar way with that of $\zeta^{k}{ }_{750}$ such as shown in (5.1) and (5.2). In Figs. 9 and 10, the computed values of spectral densities of $\zeta^{k}{ }_{500}$ for $k=2$ are shown

* Since the spectral density of $(V \cdot \nabla \zeta+\beta v)^{k}{ }_{500}$ was already discussed in the previous paper (Gambo, 1979), we do not show the result in this paper. 


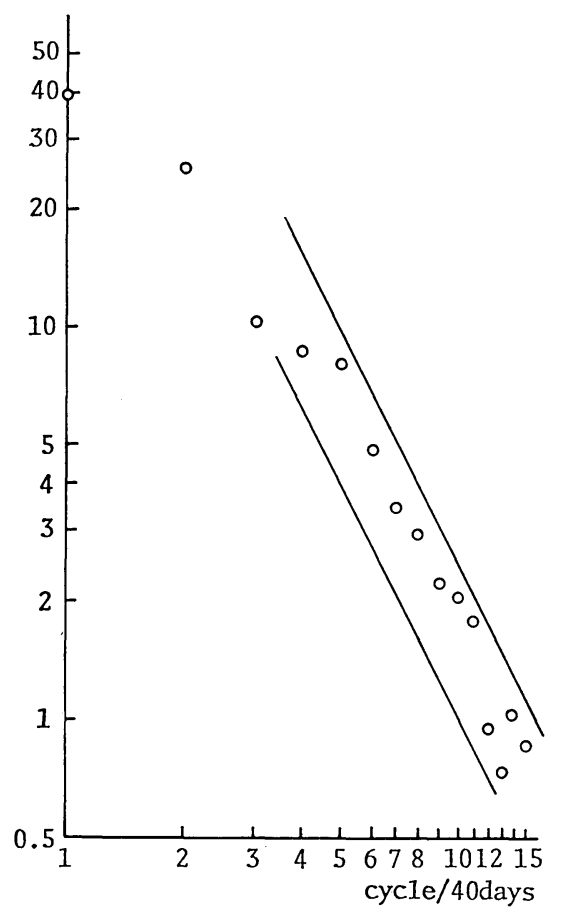

Fig. 9 Mean spectral density of $\zeta_{500}$ for $k=2$ in the frequency $(\nu)$ domain computed at $\varphi=45^{\circ}$, $50^{\circ}$ and $55^{\circ} \mathrm{N}$ in the winter season of 19711972. Units of spectral density and $\nu$ are $\left(10^{-5}\right.$ $\left.\mathrm{s}^{-1}\right)^{2} /($ cycle/day) and (cycle/40 days) respectively. Straight lines denote that the spectral density $\propto 1 / \nu^{2}$.

in two winter seasons of 1971-1972 and 19751976 respectively. The results in these figures denote the mean values of spectral densities of $\zeta^{k}{ }_{500}$ computed at $\varphi=45^{\circ}, 50^{\circ}$ and $55^{\circ} \mathrm{N}$. The straight lines which correspond to $1 / \nu^{2}$ are written in the figure for the reference. For the sake of comparison, the mean values of spectral densities of $\zeta^{k} 500$ for $k=6$ computed at $\varphi=45^{\circ}$, $50^{\circ}$ and $55^{\circ} \mathrm{N}$ in two winter seasons of 1971 1972 and 1975-1976 are shown in Figs. 11 and 12 respectively. Here the wave number $k=6$ is picked up as the representative one of baroclinic waves. As may be seen in Figs. 11 and 12 , the characteristic feature of spectral density of vorticity for $k=6$ is different from that of ultra-long waves. In the case of winter season of 1975-1976 (see Fig. 12), the maximum value of spectral density is obtained around the frequency of 4-5 cycles/40 days, i.e., the period of 8-10 days. This means that the westerlies predominated in middle latitudes in the winter season of 1975-1976 and the baroclinic waves developed in middle latitudes.

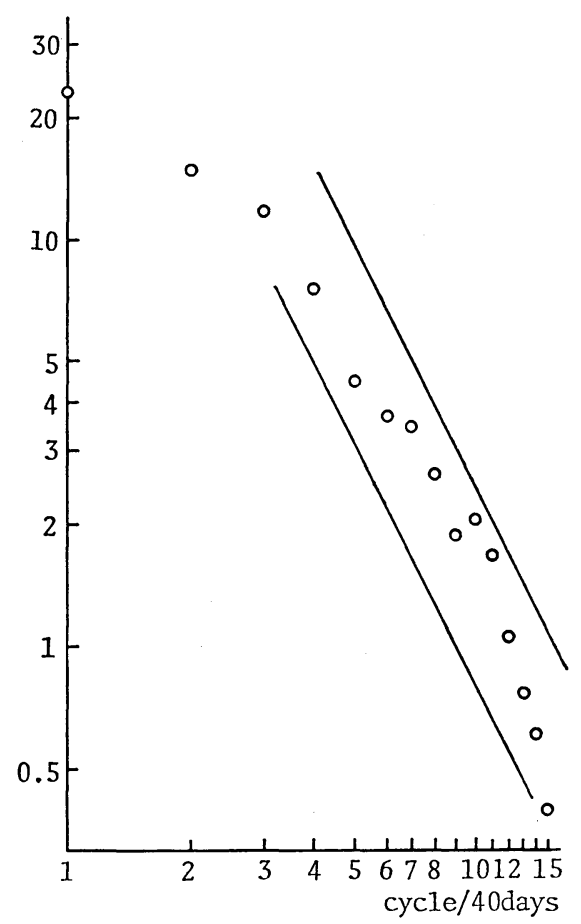

Fig. 10 As in Fig. 9 except in the winter season of 1975-1976.

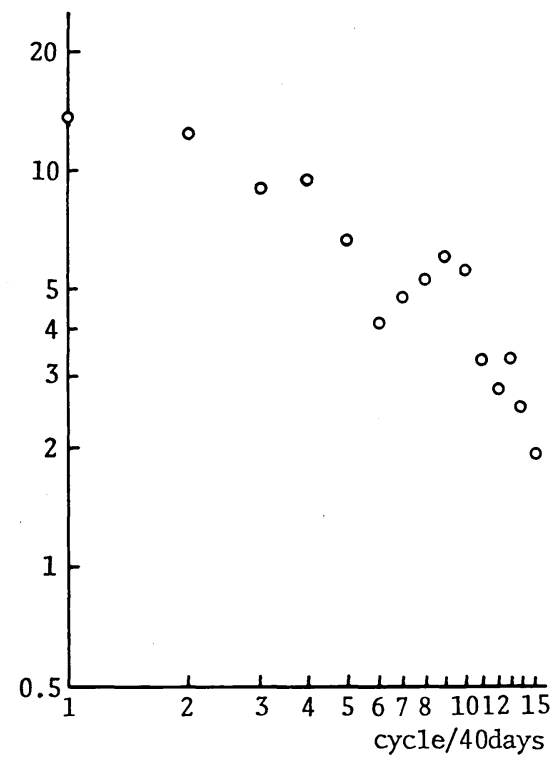

Fig. 11 As in Fig. 9 except for $k=6$.

\section{Remarks on the estimation of vertical p-velocity}

In this paper the vertical $p$-velocity, $\omega$ is obtained from the vorticity equation by making use of the observed data of $\partial \zeta / \partial t$ as mentioned in section 3 . This procedure for obtaining the 


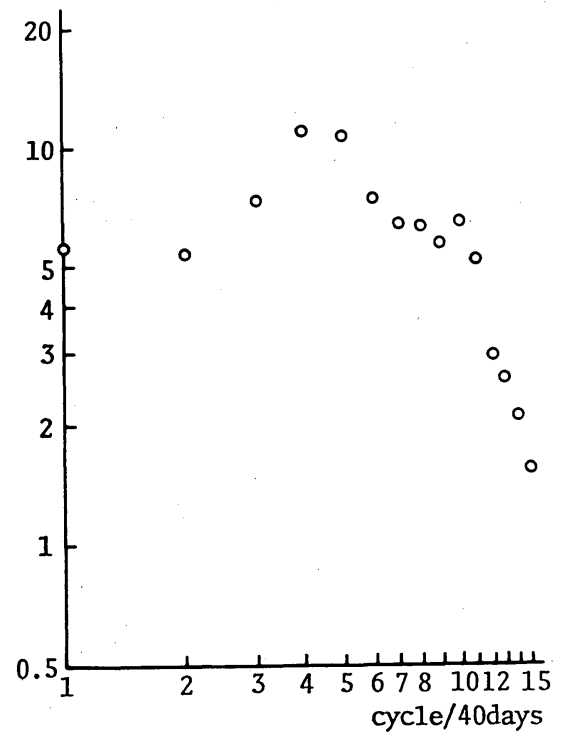

Fig. 12 As in Fig. 11 except in the winter season of 1975-1976.

value of $\omega$ was discussed by Eliassen and Hubert (1953) in the 1950's from the standpoint of synoptic analyses of precipitation and cloud amount. Therefore, in this paper we examine the monthly mean value of $\omega$ from the standpoint of estimation of geographical distribution of diabating heating in the atmosphere. The accuracy of $\omega$ obtained by (3.1.0)-(3.13) may not be good in the upper troposphere due to the insufficient data analyses. Therefore, we concentrate our discussion in the lower troposphere.

The thermodynamic equation may be written as follows:

$$
\frac{\partial T}{\partial t}+V \cdot \nabla T-\omega S=\frac{1}{c_{p}} \frac{d Q}{d t}
$$

where $T$ is the temperature, $C_{p}$ is the specific heat at constant pressure, $d Q / d t$ is the rate of diabatic heating per unit mass and $S=-(\partial T / \partial p$ $\left.-R T / c_{p} p\right)$ (R: gas constant). The term of $\partial T / \partial t$ in (6.1) at time $t$ is approximately estimated from the daily data of $T$ as follows:

$$
\frac{\partial T}{\partial t}=\frac{1}{2 \text { days }}\{T(t+1 \text { day })+T(t-1 \text { day })\}
$$

Therefore we may be able to estimate the daily value of $d Q / d t$ from (6.1) if we use the value of $\omega$ obtained from the vorticity equation. In this computation we assume that $S=$ constant $\left(0.04^{\circ} \mathrm{K} / \mathrm{mb}\right)$.

As one example of zonal distribution of $d Q / d t$,

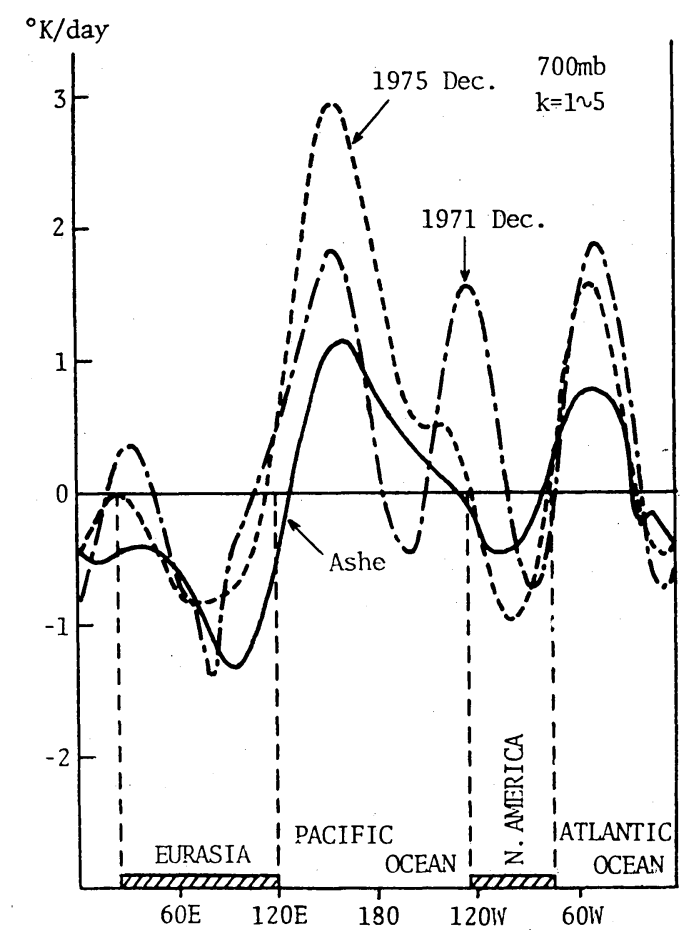

Fig. 13 Longitudinal distribution of $d Q / d t$ in Decembers of 1971 and 1975 at $\varphi=45^{\circ} \mathrm{N}$ and at $700 \mathrm{mb}$ level. Continuous lines denotes longitudinal distribution of $d Q / d t$ in January between $500 \mathrm{mb}$ and $1,000 \mathrm{mb}$ at $\varphi=45^{\circ} \mathrm{N}$ estimated by Ashe. Unit of $d Q / d t$ is expressed in ${ }^{\circ} \mathrm{K} /$ day.

we show the result at $\varphi=45^{\circ} \mathrm{N}$ and at $700 \mathrm{mb}$ level. In Fig. 13 the zonal distributions of $d Q / d t$ in Decembers of 1971 and 1975 are shown respectively. In the figure the value of $d Q / d t$ is expressed in synthesizing five components of wave numbers $k=1-5$, in order to filter out the diabatic heating due to small scales. In order to compare our result with others, the result estimated by Ashe (1979) is written in the figure. Since the value of $d Q / d t$ estimated by Ashe is the long-term mean value of $d Q / d t$ in January between $500 \mathrm{mb}$ and $1,000 \mathrm{mb}$ at $\varphi=45^{\circ} \mathrm{N}$, the direct comparison is not reasonable. However, the geographical distribution of our result seems to be reasonable compared with Ashe's result and it will be pointed that the rate of heating over the Pacific Ocean at $\varphi=45^{\circ} \mathrm{N}$ is overestimated in our case. In connection with this problem we remark that the Brown's result obtained by the similar method with ours also shows the tendency to estimate relative high value about the rate of heating over the Pacific Ocean 
(Brown, 1964), compared with the direct estimation from the precipitation and the sensible heat flux at the surface.

\section{Summary of results and discussion}

The vorticity equation of transient ultra-long waves in middle latitudes in winter is examined if there is a possibility to rewrite the same form with Langevin's equation in Brownian motion. It is shown that the vorticity equation of ultralong waves is written in the following form (see (4.6)) when we consider the case where the frequency $\nu$ is larger than 2 cycles/40 days,

$$
\frac{\partial \zeta}{\partial t}+a^{\prime} \zeta=F
$$

where $\zeta$ is the vorticity, $a^{\prime}$ is the damping coefficient and $F$ denotes the sum of the advection term of absolute vorticity and divergence term in the vorticity equation.

By making use of data in two winter seasons of 1971-1972 and 1975-1976, we examine the characteristics of the time-series of $F$ and we find that $F$ may be regarded as the random process with a white noise time-series in a sense of first approximation. In this way, the equation mentioned above may be regarded as Langevin's equation in Brownian motion. From this result we may be easily conclude that the spectral density of vorticity of transient ultra-long waves in the frequency domain is proportional to the minus second power of the frequency when $a^{\prime} \ll \nu$. This conclusion is checked from the observational data of the time-series of vorticity in two winter seasons of 1971-1972 and 19751976, and we obtain the reasonable result.

In this paper, we confine our discussion in the case of winter season and also in middle latitudes where the baroclinic waves predominate. In the future, the discussion should be expanded to the other seasons and the analyses in low and high latitudes should be done in order to obtain a better understanding about the characteristics of ultra-long waves.

\section{Acknowledgements}

The author wishes to express his sincere thanks to Dr. T. Iwashima for his patient arrangement of the NMC data and Mrs. K. Kudo for programming of the computation in this paper and also typing of the manuscript. Thanks are also extended to Mr. Y. Fujiki for drawing the figures. This paper is sponsored in part by Grant in Aid for Scientific Research from the Ministry of Education.

\section{References}

Ashe, S., 1979: A nonlinear model of the timeaverage axially asymmetric flow induced by topography and diabatic heating. J. Atmos. Sci., 36, 109-126.

Berkofsky, L. and E. A. Bertoni, 1955: Mean topographic charts for the entire earth. Bull. Amer. Met. Soc., 36, 350-354.

Brown, J. A., 1964: A diagnostic study of tropospheric diabatic heating and the generation of available potential energy. Tellus, 16, 371-387.

Derome, J. F., and A. Wiin-Nielsen, 1971: The response of a middle latitude model atmosphere to forcing by topography and stationary heat sources. Mon. Wea. Rev., 99, 564-576.

Eliassen, A. and W. E. Hubert, 1953: Computations of vertical motion and vorticity budget in a blocking situation. Tellus, 5, 196-206.

Gambo, K., 1979: A note on the spectral density of vorticity of ultra-long waves in middle latitudes at the $500 \mathrm{mb}$ level in the winter season. $J$. Meteor. Soc. Japan, 57, 373-385.

Lumley, J. L. and H. A. Panofsky, 1964: The structure of atmospheric turbulence. pp. 239, John Wiley \& Sons, Inc.

Yaglom, A. M., 1962: An introduction of the theory of stationary random functions. pp. 235, PrinceHall, Inc.

\title{
冬期中緯度における超長波のうず度方程式と ブラウン運動におけるランジュバン方程式
}

\author{
岸 保 勘 三 郎 \\ 東京大学理学部地球物理学教室
}

冬期中緯度に和ける超長波のらず度のスペクトル解析を行った。らず度の 周波数領域におけるスペクトル強 度は周波数の二乗に逆比例するのがわかった。この物理的根拠を説明するために, 超長波のうず度方程式をブラ ウン運動に扣けるランジュバン方程式の形に書き直せらるか否かを検討した。1971 年一1972 年, 1975 年一1976 年の観測データを用いて中緯度の超長波のうず度方程式を検討した結果, 超長波のうず度方程式はブラウン運動 に拈けるランジュバン方程式と同じょうに取扱えることがわかった。 